\title{
KUALITAS PELAYANAN MASYARAKAT PUSKESMAS DESA PAMARANGAN KECAMATAN TANJUNG KABUPATEN TABALONG
}

\author{
Mahriani \\ Muhammad Noor Ifansyah \\ Program Studi Ilmu Administrasi Publik \\ Sekolah Tinggi Ilmu Administrasi Tabalong \\ Jalan Komplek Stadion Olah Raga Saraba Kawa Pembataan Tanjung-Tabalong \\ Kode Pos 71571 Telp/Fax (0526) 2022484
}

\begin{abstract}
ABSTRAK
Penelitian ini ditujukan untuk mengetahui mengenai kualitas pelayanan masyarakat Puskesmas Desa Pamarangan Kecamatan Tanjung Kabupaten Tabalong. Khususnya berdasar dimensi kualitas yaitu terdiri dari variabel-variabel: reliability (kehandalan), Responsiveness (cepat tanggap), assurance (jaminan), empathy (empati), dan tangible (bukti langsung) serta kepuasan masyarakat. Variabelvariabel tersebut digunakan untuk mengetahui bagaimanakah kualitas pelayanan terhadap masyarakat yang datang berobat ke Puskesmas Pamarangan.

Tujuan Penelitian ini adalah untuk mengetahui bagaimanakah kualitas pelayanan yang diperoleh masyarakat selama berobat di Puskesmas Desa Pamarangan Kecamatan Tanjung Kabupaten Tabalong. Metode penelitian yang dilakukan adalah metode deskriptif yaitu memberikan gambaran yang sejelasjelasnya mengenai peristiwa atau kejadian yang menjadi objek penelitian, dengan menggunakan pendekatan kualitatif yaitu dengan cara memahami sifat-sifat dan fenomena yang diteliti mengenai Kualitas Pelayanan Masyarakat Puskesmas Desa Pamarangan Kecamatan Tanjung Kabupaten Tabalong, pengumpulan data yang dilakukan dengan cara observasi, angket dan dokumentasi.

Dari hasil penelitian menunjukan bahwa tingkat penilaian masyarakat yaitu (cukup baik) dengan persentasi $47.7 \%$ terhadap kualitas pelayanan yang ada di puskesmas pamarangan.
\end{abstract}

Kata kunci: Kualitas pelayanan

\section{ABSTRACT}

This research is aimed to know about the quality of service patient center of health services community (Puskesmas) village Pamarangan city Tanjung Regency Tabalong. Especially based on the quality dimension that consists of variables: reliability, responsiveness, assurance, empathy and tangible (direct evidence) and patient satisfaction. These variables are used to determine how the quality of service to patients who come to the Puskesmas treatment.

The purpose of this study was to determine how the quality of service obtained by patients during treatment at Puskesmas Village Pamarangan city Tanjung Regency Tabalong. The research method used is descriptive method that gives a clear picture of the event or event that become the object of the researcher, using qualitative approach that is by understanding the nature and the phenomenon that research about Patient Service Quality of Puskesmas Village Pamarangan city Tanjung Regency Tabalong, data collection conducted by means of observation, questionnaires and documentation.

From the results of research shows that the level of public perception that is (good enough) with a percentage of $47.7 \%$ of the quality of services available at puskesmas pamarangan.

Keywords: Service Quality

\section{PENDAHULUAN}

Menurut Undang-undang Nomor 25 Tahun 2009 tentang pelayanan publik menyebutkan bahwa pelayanan publik adalah suatu kegiatan atau serangkaian kegiatan dalam rangka pemenuhan kebutuhan 
pelayanan sesuai dengan peraturan perundang-undangan bagi setiap warga dan penduduk atas barang, jasa dan pelayanan administratif yang disediakan oleh penyelenggara pelayanan publik.

Masalah utama sebuah lembaga jasa pelayanan kesehatan yang banyak persaingan adalah pelayanan yang diberikan apakah sudah sesuai harapan masyarakat atau belum. Oleh karena itu Puskesmas Desa Pamarangan dituntut untuk selalu menjaga kepercayaan dan kepuasan masyarakat dengan meningkatkan kualitas pelayanan agar kepuasan masyarakatnya meningkat. Adapun kondisi yang menunjukan masalah di puskesmas Desa Pamarangan Kecamatan Tanjung Kabupaten Tabalong yakni adanya keluhan yang sering terdengar oleh pihak pengguna layanan ialah mengenai sikap dan tindakan dokter ataupun perawat yang kurang cepat tanggap, sarana yang kurang memadai, keterlambatan proses pelayanan yang diberikan, keterbatasan obat, dan lain lain.

Terciptanya kualitas layanan tentunya akan menciptakan kepuasan terhadap pengguna layanan. Kualitas layanan ini pada akhirnya dapat memberikan beberapa manfaat, diantaranya terjalinyan hubungan yang harmonis antara penyedia barang dan jasa dengan masyarakat, serta memberikan dasar yang baik bagi terciptanya loyalitas masyarakat dan membentuk suatu rekomendasi dari mulut ke mulut yang menguntungkan bagi penyedia jasa tersebut.

Menurut Zeithaml, Berry dan Parasuraman (2005: 10-11) dimensi kualitas yang dimaksud adalah reliability (keterandalan), responsiveness (capat tanggap), assurance (jaminan), empaty (empati), dan tangible (nyata). Untuk dapat menentukan kebijakan pelayanan yang tepat, khususnya dalam pelayanan kepada masyarakat, diperlukan kajian tentang dimensi kualitas pelayanan kepada masyarakat Puskesmas Desa Pamarangan Kecamatan Tanjung Kabupaten Tabalong.

Sehubungan dengan kondisi itu, permasalahannya adalah untuk mengetahui bagaimanakah kualitas pelayanan yang diberikan terhadap pasien berdasarkan dimensi reliability, responsiveness, assurance, empaty dan tangible di Puskesmas Desa Pamarangan selama ini.

Studi ini perlu dilakukan dalam rangka dapat memberikan manfaat sebagai sumbangan pemikiran kepada instansi pemerintah penyedia layanan kesehatan dalam upaya peningkatan pelayanan kepada pasien (masyarakat), memberikan pertimbangan bagi pihak manajemen dalam pengambilan keputusan tentang hubungan perbaikan kinerja pelayanan di Puskesmas Desa Pamarangan Kecamatan Tanjung Kabupaten Tabalong, Dengan begitu kompleknya masalah kehidupan sekarang ini, menyebabkan masalah kesehatan benar-benar menjadi merupakan kebutuhan penting. Oleh karena itu penyedia jasa kesehatan diharapkan mampu untuk selalu konsisten pada peranya, terutama kuantitas dan kualitas pelayanan dalam upaya memuaskan kebutuhan dan keinginan masyarakat. 


\section{KONSEP KUALITAS}

Membicarakan tentang pengertian atau definisi kualitas dapat berbeda makna bagi setiap orang, karena kualitas memiliki banyak kriteria dan sangat tergantung pada konteksnya. Banyak pakar dibidang kualitas yang mencoba untuk mendefinisikan kualitas berdasarkan sudut pandangnya masing-masing.

Menurut Nursya'bani Purnama (2006: 15-16) menentukan kualitas produk harus dibedakan antara produk manufaktur atau barang (goods) dengan produk layanan (service) karena keduanya memilki banyak perbedaan. Menyediakan produk layanan (jasa) berbeda dengan menghasilkan produk manufaktur dalam beberapa cara. Perbedaan tersebut memiliki implikasi penting dalam manajemen kualitas. Perbedaan antara produk manufaktur dengan produk Layanan adalah:

1. Kebutuhan konsumen dan standar kinerja sering kali sulit di identifikasi dan diukur, sebab masingmasing konsumen mendefinisikan kualitas sesuai keinginan mereka dan berbeda satu dengan lain.

2. Produksi layanan memerlukan tingkatan "customization atau individual customer" yang lebih tinggi dibanding manufaktur. Dalam manufaktur sasarannya adalah keseragaman. dokter, ahli hukum, personal penjualan asuransi, dan pelayanan restoran, harus menyesuaikan layanan mereka terhadap konsumen individual.

3. Output sistem layanan tidak terwujud, sedangkan manufaktur berwujud. Kualitas produk manufaktur dapat diukur berdasar spesifikasi desain, sedangkan kualitas layanan pengukurannya subyektif menurut pandangan konsumen, dikaitkan dengan harapan dan pengalaman mereka. Produk manufaktur jika rusak dapat ditukar atau diganti, sedangkan produk layanan harus diikuti dengan permohononan maaf dan reparasi.

4. Produk layanan diproduksi dan dikonsumsi secara bersama-sama, sedangkan produk manufaktur diproduksi sebelum dikonsumsi. Produk layanan tidak bisa disimpan atau diperiksa sebelum disampaikan kepada konsumen.

5. Konsumen seringkali terlibat dalam proses layanan dan hadir ketika layanan dibentuk, sedangkan produk manufaktur dibentuk diluar keterlibatan langsung dari konsumen. Misalnya konsuman restoran layanan cepat menempatkan ordernya sendiri atau mengambil makanan sendiri, membawa makanan sendiri kemeja, dan diharapakan membersihkan meja ketika setelah makan.

6. Layanan secara umum padat tenaga kerja, sedangkan manufaktur lebih banyak padat modal. Kualitas interaksi antara produsen dan konsumen merupakan faktor vital dalam penciptaan layanan. Misalnya kualitas layanan kesehatan tergantung interaksi pasien, perawat, dokter, dan petugas kesehatan lain. Di sini perilaku dan moral pekerja merupakan hal yang kritis dalam menyediakan kualitas layanan.

Kualitas jasa pelayanan sangat dipengaruhi oleh harapan konsumen. Harapan konsumen dapat bervariasi dari konsumen satu dengan konsumen lain walaupun pelayanan yang diberikan konsisten. Kualitas mungkin dapat dilihat sebagai suatu kelemahan kalau konsumen mempunyai harapan yang terlalu tinggi, walaupun dengan suatu pelayanan yang baik. 
Menurut Wyckof (Lovelock, 2006: 19-20) memberikan pengertian kualitas layanan sebagai tingkat kesempurnaan tersebut untuk memenuhi keinginan konsumen. Sementara menurut Parasuraman, kualitas layanan merupakan perbandingan antara layanan yang dirasakan (persepsi) konsumen dengan kualitas layanan yang diharapkan konsumen. Jika kualitas layanan yang dirasakan sama atau melebihi kualitas layanan yang diharapkan, maka layanan dikatakan berkualitas dan memuaskan.

Banyak organisasi layanan harus menangani sangat banyak transaksi konsumen. Misalnya pada hari-hari tertentu, sebuah bank mungkin harus memproses jutaan transaksi nasabah pada berbagai kantor cabang dan mesin bank atau barangkali Perusahaan jasa kiriman harus menangani jutaan paket kiriman diseluruh dunia.

Beberapa diantaranya yang paling populer adalah yang dikembangkan oleh tiga pakar kualitas tingkat internasional, yaitu mengacu pada pendapat W.Edwards Deming, Philip B. Crosby dan Joseph M. Juran (2005: 7)

1. W. Edwards Deming (2005: 7) mendefinisikan kualitas adalah apapun yang menjadi kebutuhan dan keinginan konsumen Philip B. Crosby (1996: 337) mempersepsikan kualitas sebagai nihil cacat, kesempurnaan dan kesesuaian terhadap persyaratan.

2. Juran (2005: 7) mendefinisikan kualitas sebagai kesesuaian terhadap spesifikasi, jika dilihat dari sudut pandang produsen. Sedangkan secara obyektif kualitas adalah suatu standar khusus dimana kemampuannya (availability), kinerja (performance), kendalannya (reliability), kemudahan pemeliharaan (maintainability) dan karakteristiknya dapat diukur.

3. Gaspersz (2002: 181) mendefinisikan kualitas totalitas dari karakteristik suatu produk (barang dan atau jasa) yang menunjang kemampuan untuk memenuhi kebutuhan yang dispesifikasikan.

Zeithaml, Berry dan Parasuraman (Zulian Yamit, 2005: 10-12) telah melakukan berbagai penelitian terhadap beberapa jenis jasa, dan berhasil mengidentifikasi lima dimensi karakteristik yang digunakan oleh para masyarakat dalam mengevaluasi kualitas pelayanan. Kelima dimensi karakteristik kualitas pelayanan tersebut adalah:

1. Reliability (kehandalan), yaitu kemampuan dalam memberikan pelayanan dengan segera dan memuaskan serta sesuai dengan telah yang dijanjikan.

2. Responsiveness (daya tangkap), yaitu keinginan para staf untuk membantu para masyarakat dan memberikan pelayanan dengan tanggap.

3. Assurance (jaminan), yaitu mencakup kemampuan, kesopanan dan sifat dapat dipercaya yang dimiliki para staf, bebas dari bahaya, resiko ataupun keragu-raguan.

4. Empathy, yaitu meliputi kemudahan dalam melakukan hubungan, komunikasi yang baik, dan perhatian dengan tulus terhadap kebutuhan masyarakat.

5. Tangibles (bukti langsung), yaitu meliputi fasilitas fisik, perlengkapan, pegawai, dan sarana komunikasi. 
Dimensi kualitas yang dikemukakan oleh Zeithaml, Berry dan Parasuraman tersebut berpengaruh pada harapan masyarakat dan kenyataan yang mereka terima. Jika kenyataannya masyarakat menerima pelayanan melebihi harapannya, maka masyarakat akan mengatakan pelayanannya berkualitas dan sebaliknya.

\section{METODE PENELITIAN}

Dalam penelitian ini jenis penelitian yang digunakan yaitu Deskriptif Kualitatif. Deskriptif Kualitatif adalah memberikan gambaran atau menyajikan data yang sesuai dengan keadaan objek yang sebenarnya. Sementara itu populasi yang dimaksudkan dalam penelitian ini adalah 485 masyarakat yang datang berobat ke Puskesmas minimal dua kali berobat berdasarkan data tahun 2016.

Berdasarkan pendapat Roscoe seperti dikutip Sekaran (2000) bahwa ukuran sampel lebih besar dari 30 dan kurang dari 500 telah mencukupi untuk digunakan dalam semua penelitian. Masyarakat yang dijadikan sampel adalah 35 Orang yang datang berobat atau yang pernah menggunakan jasa pelayanan kesehatan Puskesmas Desa Pamarangan. Teknik pengambilan sampel ditentukan dengan simple random sampling yaitu pengambilan sampel informan dari sampel secara acak.

Analsisi Data

Arikunto (1998: 236) menjelaskan bahwa yang dimaksudkan dengan analisis data adalah pengolahan data yang diperoleh dengan menggunakan rumus-rumus atau aturan-aturan yang ada sesuai dengan pendekatan penelitian atau desain yang diambil.Analisis data yangdigunakan dalam penelitian adalah Teknik analisis deskriptif kualitatif yaitu dengan perolehan persentase karena penelitian ini bersifat deskriptif dan mendeskripsikan tentang variabel bebas dan variabel terikat.

\section{PEMBAHASAN HASIL PENELITIAN}

Puskesmas Pamarangan Kecamatan Tanjung Kabupaten Tabalong terletak di Jalan Akhmad Yani Desa Pamarangan berjarak $\pm 9 \mathrm{~km}$ dari Kota Tanjung/Dinas Kesehatan Kabupaten, Berjarak \pm 10 km dari RSUD Tanjung, dan \pm 240 -an km dari RSUD Ulin Banjarmasin. Didirikan pada 1970-an, secara geografis wilayah kerja Puskesmas melingkupi 1 (satu) kelurahan dan 4 (empat) desa.

Luas wilayah kerja Puskesmas Pamarangan Kecamatan Tanjung adalah 124,33 Km². Dengan wilayah terluas adalah Pamarangan Kiwa 32,30 $\mathrm{Km}^{2}$ dan wilayah terkecil adalah Banyu Tajun dengan 15,60 $\mathrm{Km}^{2}$. Pada Puskesmas Pamarangan terdapat 37orang petugas (aparatur) yang melayani masyarakat. 
Berdasarkan hasil penelitian didapat hasil sebagai berikut:

\begin{tabular}{|c|l|c|c|c|c|c|}
\hline No & \multicolumn{1}{|c|}{ Kategori } & $\begin{array}{c}\text { Sangat } \\
\text { baik }\end{array}$ & Baik & $\begin{array}{c}\text { Cukup } \\
\text { baik }\end{array}$ & $\begin{array}{c}\text { Tidak } \\
\text { baik }\end{array}$ & $\begin{array}{c}\text { Sangat } \\
\text { tidak } \\
\text { baik }\end{array}$ \\
\hline 1 & $\begin{array}{l}\text { Kualitas pengobatan secara kecepatan } \\
\text { dan ketepatan }\end{array}$ & 8,6 & 65,7 & 25,7 & 0 & 0 \\
\hline 2 & $\begin{array}{l}\text { Kualitas pengadministrasian } \\
\text { masyarakat yang berobat }\end{array}$ & 0 & 40,0 & 60,0 & 0 & 0 \\
\hline 3 & $\begin{array}{l}\text { Kualitas pelayanan tenaga medis } \\
\text { terhadap keluhan masyarakat }\end{array}$ & 0 & 22,8 & 68,6 & 8,6 & 0 \\
\hline 4 & $\begin{array}{l}\text { Kualitas Penyampaian prosedur } \\
\text { informasi }\end{array}$ & 0 & 25,7 & 60,0 & 14,3 & 0 \\
\hline 5 & Kualitas pemberian jaminan & 8,6 & 42,9 & 48,6 & 0 & 0 \\
\hline 6 & Kualitas penarikan tarif biaya & 0 & 42,9 & 51,4 & 5,7 & 0 \\
\hline 7 & Kualitas kemudahan akses pelayanan & 2,9 & 45,7 & 51,4 & 0 & 0 \\
\hline 8 & $\begin{array}{l}\text { Kualitas kesungguhan dalam } \\
\text { memberikan perhatian terhadap } \\
\text { masyarakat }\end{array}$ & 17,1 & 48,6 & 31,4 & 2,9 & 0 \\
\hline 9 & $\begin{array}{l}\text { Kualitas perlengkapan medis yang } \\
\text { memadai }\end{array}$ & 0 & 54,3 & 45,7 & 0 & 0 \\
\hline 10 & $\begin{array}{l}\text { Kualitas kondisi dan kenyamanan } \\
\text { tempat dan ruangan }\end{array}$ & 11,4 & 45,7 & 34,3 & 8,6 & 0 \\
\hline & Jumlah & 4,86 & 43,4 & 47,7 & 4,01 & 0 \\
\hline & & & & & \\
\hline
\end{tabular}

Dari tabel rekapitulasi di atas hasil kuesioner untuk mengukur kualitas pelayanan yang ada di Puskesmas Pamarangan yang diberikan kepada sampel berjumlah 35 orang yang datang berobat ke Puskesmas Pamarangan menunjukan bahwa kualitas pelayanan terhadap kepuasan masyarakat yang diselenggarakan oleh Puskesmas Pamarangan mendapatkan penilaian cukup baik dari masyarakat yang datang berobat di Puskesmas Pamarangan tersebut, hal ini terlihat dari hasil prosentase terbesar $47.7 \%$.

1. Pelayanan kehandalan (reliability)

Merupakan tanggapan masyarakat terhadap kehandalan kinerja karyawan (perawat dan petugas puskesmas) dalam hal kecepatan dan ketepatan dalam pelayanan pemeriksaan dan pengobatan terhadap masyarakat dan kegiatan administrasi yang dilakukan. Oleh karena itu kehandalan kinerja 
tenaga medis dengan cepat dan tepat dalam hal memeriksa dan mengobati masyarakat sangat diperlukan, yang artinya pengobatannya tersebut tepat sasaran. Begitu pula dengan kegiatan administrasi yang dilakukan tenaga medis baik dalam hal pencatatan absensi masyarakat yang datang dan lain-lain. Dari dua item pertanyaan tersebut untuk kemampuan pemeriksaan dan pengobatan secara cepat dan tepat terhadap masyarakat sebesar $65.7 \%$ informan menilai baik, dan untuk kegiatan administrasi yang dilakukan selama ini sebesar $60.0 \%$ informan menilai baik.

2. Pelayanan daya tangkap (responsiveness)

Merupakan kemampuan tenaga medis dalam memberikan tanggapan yang baik dan cepat terhadap keluhan masyarakat serta penyampaian informasi yang jelas dan mudah dimengerti, oleh karena itu tanggapan yang cepat perlu dilakukan oleh tenaga medis terhadap keluhan masyarakat agar masyarakat tersebut tidak merasa terlalu lama menunggu untuk diberikan pengobatan. Begitu pula diperlukan adanya penyampaian informasi yang jelas dan mudah dimengerti agar masyarakat yang berobat tidak merasa kebinggungan dengan prosedur yang tersedia di Puskesmas Pamarangan tersebut. Dari dua item pertanyaan tersebut yang mana untuk merespon keluahan masyarakat sebesar $62.9 \%$ informan menilai baik dan untuk penyampaian informasi yang jelas dan mudah dimengerti berdasarkan prosedur yang ada sebesar $60.0 \%$ informan menilai baik.

3. Pelayanan jaminan (assurance)

Merupakan kemampuan dari pihak Puskesmas Pamarangan dalam memberikan jaminan apabila terjadi kesalahan pada hasil kinerja tenaga medis terhadap masyarakat, dan penarikan tarif biaya yang sesuai dengan kualitas pelayanan yang diterima. Oleh karena itu pemberian jaminan tersebut sangat diperlukan agar masyarakat merasa puas dengan pelayanan dikarenakan adanya tanggung jawab dari pihak medis yang bersangkutan, begitu pula penarikan tarif biaya yang sesuai dengan kualitas pelayanan yang diterima masyarakat, agar masyarakat tidak merasa keberatan dengan tarif biaya yang harus di bayar. Dari dua item pertanyaan tersebut dalam segi pemberian jaminan terhadap masyarakat sebesar 48,6 \% informan menilai cukup baik,dan untuk penarikan tarif biaya yang sesuai dengan pelayanan yang diterima sebesar 51,4 \% informan menilai cukup baik.

4. Pelayanan hubungan komunikasi yang baik (Empathy)

Merupakan kemampuan dari pihak puskesmas pamarangan dalam memberikan kemudahan pelayanan dalam akses pelayanan kesehatan yang mudah dijangkau oleh masyarakat, dan kemampuan tenaga medis dalam memberikan perhatian kepada masyarakat yang berobat. Oleh karena itu dengan adanya akses yang mudah dijangkau oleh masyarakat, sehingga dapat memberikan kemudahan bagi masyarakat untuk berobat dan juga adanya pemberian perhatian kepada masyarakat yang berobat sehingga membuat masyarakat merasa diperdulikan, dari dua item tersebut sebanyak $51.4 \%$ dari informan menilai cukup baik dalam kemampuan memberikan 
kemudahan akses pelayanan kesehatan, dan $48.8 \%$ informan menilai cukup baik untuk kemampuan memberikan perhatian kepada masyarakat.

5. Pelayanan bukti langsung (tangible)

Bukti langsung yang di maksud disini adalah berupa tersedianya fasilitas-fasilitas yang ada di Puskesmas Pamarangan yang mana dapat dirasakan manfaatnya oleh masyarakat saat berobat, dimana fasilitas tersebut mampu membantu tenaga medis dalam hal pemberian pelayanan terhadap masyarakat. Dari dua item tersebut untuk perlengkapan peralatan medis yang memadai sebesar 54,3 $\%$ informan menilai cukup baik, dan untuk kondisi dan situasi puskesmas seperti tersedianya ruangan,tempat parker dan toilet yang memadai sebesar $45,7 \%$ informan menilai cukup baik.

\section{SIMPULAN}

Dari hasil penelitian yang penulis lakukan dapat disimpulkan bahwa kualitas pelayanan masyarakat Puskesmas Desa Pamarangan Kecamatan Tanjung Kabupaten Tabalong pada masyarakat sekitarnya yang telah berobat sudah cukup baik, hal ini dapat dilihat dari hasil prosentase rata-rata yaitu $47.7 \%$.

Penulis berharap Puskesmas mampu untuk meningkatkan kualitas layanan agar lebih mempertahankan tingkat layanan yang memuaskan, dalam hal pelayanan pemeriksaan dan pengobatan yang dilakukan secara cepat dan tepat. Puskesmas Desa Pamarangan perlu secara rutin mengamati pelayanannya agar dapat mempertahankan kelebihan-kelebihan yang ada dan selalu meningkatkan kualitas pelayanan pada variabel-variabel yang masih kurang penilaiannya atau menurut penilaian pasien belum sesuai dengan yang diharapakan oleh pasien, hal ini bisa dilakukan dengan lebih memperhatikan terhadap kebutuhan dan keinginan pasien, peningkatan fasilitas sarana dan prasarana, jaminan rasa aman, nyaman, dan kepercayaan serta pelayanan yang dijanjikan secara cepat, akurat dan pasti sehingga akan meningkatkan kepuasan pasien.

Semua unsur dimensi kualitas pelayanan diatas mempunyai pengaruh positif dan signifikan terhadap kepuasan pasien sehingga Puskesmas Desa Pamarangan perlu memperhatikan lebih khusus dimensi-dimensi tersebut serta mencari terobosan baru yang dapat meningkatkan kepuasan pasien.

\section{DAFTAR PUSTAKA}

Assauri, Sofjan, 2003, Customer Service yang Baik Landasan Pencapaian Customer Satisfaction dalam Usahawan, Gramedia: Jakarta.

Crosby, 1984, Manajemen Kualitas Pelayanan, STIA LAN Press, Jakarta

Deming, W.Edward, 2005.Manajemen Kualitas Produk dan Jasa, Edisi Pertama, cetakan keempat, Penerbit Ekonisia Kampus Fakultas Ekonomi UII Yogyakarta

Departemen Kesehatan Republik Indonesia, 2003, Pedoman PelaksanaanJaminan Mutu di Puskesmas, Direktorat Jenderal Pelayanan Medik, Jakarta. 
Gaspersz, Vincent, 2002, Manajemen Kualitas dalam Industri Jasa, Gramedia.Jakarta.

Gronroos, 2006, Manajemen Kualitas Perspektif Global, Edisi Pertama, Cetakan Pertama, Penerbit Ekonisia Kampus Fakultas Ekonomi UII Yogyakarta.

Juran, 2005, Manajemen Kualitas Produk dan Jasa, Edisi Pertama, cetakan keempat, Penerbit Ekonisia Kampus Fakultas Ekonomi UII Yogyakarta

Kotler, Philip, 2000, Marketing Management, (Edisi Indonesia oleh Hendra Teguh, Ronny dan Benjamin Molan), PT Indeks, Jakarta.

Purnama, Nursya,bani, 2006, Manajemen Kualitas Perspektif Global, Edisi Pertama, Cetakan Pertama, Penerbit Ekonisia Kampus Fakultas Ekonomi UII Yogyakarta.

Sekaran, Uma, 2000, Research, Methods for Business, A Skill - Building Approac. (Third Edition), John Wiley \& Sons, Inc. Singapore.

Tjiptono, Fandi dan Gregorius Candra, 2005, Service, Quality, and Satisfaction, Andi Offset: Yogyakarta.

UPT. Puskesmas Kecamatan Tanjung, 2013, Profil Kesehatan UPT. Puskesmas Kecamatan Tanjung, Tanjung

Wyckof, 2006, Manajemen Kualitas Perspektif Global. Edisi Pertama, Cetakan Pertama. Penerbit Ekonisia Kampus Fakultas Ekonomi UII Yogyakarta.

Walker, Dennis, 1997, Mendahulukan Masyarakat, Gramedia, Jakarta.

Yamit, Zulian, 1996, Manajemen Produksi dan Operasi, Edisi Pertama, Penerbit Ekonisia Kampus Fakultas Ekonomi UII Yogyakarta. 